\title{
An Overview of Sustainable Design Factors in High-Rise Buildings
}

\author{
Farzad Navaei \\ Department of Architecture, Islamic Azad University of Ajabshir, Tabriz, Iran
}

\section{Email address:}

f.navaiee@gmail.com

\section{To cite this article:}

Farzad Navaei. An Overview of Sustainable Design Factors in High-Rise Buildings. International Journal of Science, Technology and Society. Special Issue: Research and Practice in Architecture and Urban Studies in Developing Countries. Vol. 3, No. 2-1, 2015, pp. 18-23. doi: $10.11648 /$ j.ijsts.s.2015030201.14

\begin{abstract}
Nowadays population growth and increase of land cost have made it inevitable for the cities to construct tall building or vertical development or growth. Among the advantages of vertical expansion of the cities are saving cultivable land to supply needed food for increasing population, reducing environmental destruction due to reduced construction on natural land, reduce in transportation and urban traffic as well as reduce in energy consumption and air pollution caused by horizontal expansion of the cities. This paper examines relationship between high-performance tall building architecture and environment applying innovative technology. Research method of present investigation is descriptive. It is concluded that the future of the built environment depends on the methods and techniques used by engineers and architects to design sustainable environment and intelligent building.
\end{abstract}

Keywords: Sustainable Architecture, High-Rise Buildings, Environment, Green Architecture, Technology Transfer

\section{Introduction}

Nowadays, environment saving in fossil energies consumption and sustainable development have changed to the most common and important issues in the international conventions. Moreover, continuous increase in the world population has confronted the nations with the energy shortage more than ever and this threatens human's life [1]. According to the PNUD (Program of the United Nations for the Development) until 2030, in urban areas throughout the world 5 billion people will live. Whereas in 1950, 30 percent of the world population lived in urban areas, and in 2000 the proportion of the urban dwellers climbed to $\% 47$ and it is projected to rise to 60 per cent until 2030 [2]. Energy shortage, global warming, urban sprawl, air pollution, overflowing landfills, water shortage and disease will be the legacy of the twenty-first century, unless we move quickly towards the notion and implementation of sustainability.

Considering the increased population and its consequences, the vertical development of the cities seems the best and inevitable solution for the problem which will change our urban design method for ever. Due to the importance of environment issue, green architecture and sustainable architecture affects our present and future design. This vertical development will be effective when it is designed sustainable.

\section{The Concept of Sustainable Development and Architecture}

Sustainable development is a wide and ideal term which has various and different meanings. Consequently, different meanings of the term, requires different reactions of the thinkers. In 1983, the United Nations established the World Commission Environment and Development in attempt to resolve the conflicts arising out of the aspirations of the developing and developed worlds. In 1989 they published "Our Common Future" or the Brundtland Report, which launched the concept of "Sustainable Development" and was reinforced in 1992 at Earth Summit in Rio. It called for "Development which meets the needs of the present generation without compromising the ability of future generations to meet their own needs." Sustainability essentially aims for ecological balance [3].

Sustainable development relies on three main principles: environmental sustainability, economical sustainability and social sustainability. The principle of environmental sustainability relies on the fact that, land should be used in the way that it would be also usable for the next generation. Human activities should be done without lessening resources 
and increasing environmental destruction, Hence the recyclability of the natural resources should be taken into consideration when using them. Environmental sustainability development emphasizes on the reduce in using of natural resources, renewable energies, prevention of energy resources loss, reduce in production waste and emphasizes on reusing and recycling wastes, using materials which can be returned to the nature and thus, reduction of pollution production in industries and agriculture [4].

Sustainable architecture is not a style rather it is a holistic approach which focuses on the interactive relationship between the building and its field context. Sustainable architecture is a logical reaction to difficulties and problems arose in industrial era. Such definitions consider sustainability as the most important purpose of the architecture and introduce reducing energy using and natural resources conservation for future generations as the most important and necessary measures taken to achieve sustainable patterns in architecture [4]. Sustainable architecture is an informed and Economical environment in energy consumption, using renewable, respondent systems and materials. Ecological and environmental concerns beyond the issue of nonrenewable energy resources consumption have been developed widely [3].

Following principles are those which should be taken into consideration in a building to make it become among sustainable building classification: First principal: saving energy, second principal: compatibility with climate, third principal: reducing new resources consumption, forth principal: supplying needs of dwellers, fifth principal: compatibility with site, sixth principal: being holistic [1].

\section{The High Performance Tall Buildings}

Tall buildings are massive consumers of the energy. They are the dominant elements in urban architecture due to their scale and purpose, and should be the focus of sustainable design. So many architects (such as Ken Young) believe that, the danger of skyscrapers to the environment is more threatening than air pollution, so they propose green architecture to prevent such problem. The Lack of space and the population growth are the main problems which are threatening the environment, seriously. Skyscrapers and other mega structures which are built to keep balance of population growth and needed space, consume considerable amount of energy in construction process and next that, resulting in environmental pollution and overflow of the wastes and generally they deprive their dwellers of natural weather and light. Meanwhile most designers, engineers and architects believe that, if the buildings of big and populated cities are designed and built under appropriate conditions, they can indicate sustainable development and green architecture. Believing in such attitude, inappropriate factors influencing the environment will be minimized while keeping health and welfare of the dwellers [5].

Clearly, the design process is significantly complex since the designer has to understand the building performance in terms of different design factors and variables and under differing conditions. Some overall benefits of high performance design are: energy efficiency, design flexibility, resource conservation, indoor environmental quality, etc. [6].

The principal design factors that are crucial for achieving a high performance tall building are: site context, environment, structure and use of materials, energy consumption, use of water, ecological balance, community development, etc. Because of these diverse aspects of design for tall buildings which have enormous scales as a building type, the amount of information that guides the design is often very complex, and shared by professionals of different disciplines. Further, the design factors assume different forms, such as conceptual, schematic, physical, economic, environmental, and socio-cultural. This demands smart and integration design, which hold the key to high performance buildings [7].

The design team comprising different professionals must aim for the common goal set early on that "the building will offer optimum performance" and must have a respect and understanding for each other's mission [7]. Integration and rigidness of an elegant building produces such strategies. Building construction requires solidarity and integration. It is such integrations and rigidness that result in change of mental structure of the human. In most cases, green buildings are defined as the building which has less negative effects on its surrounding environment [8].

\section{Strategies for Achieving Sustainability}

In most countries, sustainable development and specifically sustainability in architecture, design and implementation of buildings compatible with environment are the main and macro issues. Thus, some countries which are leading of this field, has thought about designing an evaluation system immediately. Nowadays various ranking and evaluation methods have been developed for building sustainability evaluation in in all over the world. Systems such as Leadership in Energy and Environmental Design (LEED), Building Research Establishment Environmental Assessment Methodology (BREEAM) and Polar Environment Atmospheric Research Laboratory (PEARL)are of this type that we will introduce hereunder the most important and applied system (i.e. LEED point system).

LEED is a term which means the management of energy and environmental design. LEED certificate was developed by U.S Green Building Council. The first edition of LEED certificate was used to evaluate green buildings in 1998 . Although LEED certificate is called U.S standard for evaluation of green buildings, international community also accepted it as a criteria of evaluation in designing construction and establishment of buildings which claimed green function to surrounding environment [10].

LEED presents solutions in seven chapter and the buildings which observing following items be succeeded to get LEED certification for green buildings and they are ranked based on their obtained point. The main indicators of maximum point are: sustainable sites, water performance and efficiency, 
energy and atmosphere, materials and resources, indoor air quality, innovation and design/build process and regional

priorities “(Table 1") [10].

Table 1. LEED Certificate Checklist

\begin{tabular}{ll}
\hline Main Indicator & Criteria Ratings \\
\hline & $\begin{array}{l}\text { Preventing pollution while construction (obligatory), the appropriate site selection, obtaining optimal density in } \\
\text { built environments and vicinity to urban services, restoration of damaged sites and environmental pollutions, } \\
\text { providing easy access to public transportation systems, invention appropriate parking capacity, maximizing } \\
\text { outdoor, qualitative and quantitative management of rainfall, preventing heat island in non-roofed buildings and } \\
\text { preventing heat island in roofed buildings, Reducing light pollutions. }\end{array}$ \\
& Reducing water consumption (obligatory), saving water consumption of irrigation systems, waste recycle by using \\
the innovative technologies. & \\
Assurance of energy systems performance accuracy in the buildings (obligatory), minimum use of energy in the \\
buildings (obligatory), preventing reduction of ozone layer through cooling instruments(obligatory) optimization \\
of energy consumption in the buildings, using renewal energy resources, distinguished and evaluated energy \\
consumption in building. \\
Gnergy \\
Gathering and saving renewable material (obligatory), reuse of the building with keeping non-structure elements of \\
indoor building, managing wastes produced by construction, using recycled materials, using local materials, using \\
materials with immediate recyclability. \\
Achieve to minimum desired air quality of indoor building (obligatory), controlling the amount of tobacco smoke \\
released of the environment (obligatory), installing carbon dioxide measurement systems of building output air \\
flow, increasing ventilation system, managing the quality of indoor air before operation of the building and at the \\
time of construction, using materials with less pollution (including adhesives and linings, colours and covers, \\
roofing and wooden products), controlling lighting systems, controlling heat and ventilation systems, heat comfort \\
system design, providing natural light, providing appropriate view. \\
Innovation in designing with the desired LEED factors \\
Importance to the local priorities.
\end{tabular}

\section{Other Strategies for Tall Green Buildings}

\subsection{Harnessing Solar Energy}

Technologies related to solar energy harnessing, convert and distribution are divided into active and inactive parts, based on its application and use type. Active operation type of solar energy involves using solar photovoltaic panels and or solar heating of the absorption panels. The second type of such technology is related to water heating through solar light absorption, steaming and use of generated steam power to produce electricity. Among the inactive methods of solar energy absorption is making buildings to the sun and using materials involving heating and pyrophoric components.

The application of photovoltaic technology for tall buildings can be significant since they provide an opportunity for a clear path of direct sunlight by towering over other buildings [7].

Maximum advantage can be taken of daylight by shaping the plan arrangement of a building to suit the activities within. The Service center of a building should be in the place where has access to daylight, natural ventilation in its lobby, elevator and staircases [11].

\subsection{Structure and Material Preferences}

At first sight it is hard to relate sustainability to the structure of a tall building. However, steel and reinforced concrete buildings are typically the materials of choice. In addition to, the core provides structural stability and its positioning is important for sustainability [11]. For example, concrete structures can be used for controlling of the cold nights in desert climates and convert it into the cooling energies at day hours. Also, steel frames can be built with recycled materials [12].

\subsection{Façade and Opening Technology}

Daylighting and shading are usually the key aspects to façade design for typical green buildings. The façade covers over 90 to 95 percent of the external building surface area in a tall building. Thus, the energy gain or loss for a tall building depends very much upon the materiality and technology employed in the façade treatment. Facades not only offer the aesthetic look and the building's architectural expression, but it can also be advantageously used to control the internal conditions of the building [7]. Hence it is better to build openings to North-South, except they could have better view in other areas. In the areas that are not affected by adequate sunlight, they should be closed walls.

It is common the application of two layer coating, sometimes three layer coating and view with ventilation system [13]. Double glazing with argon filled cavities, triple glazing and glass coating increase U Values [14].

\subsection{Orientation and Walls}

Skyscrapers are strongly influenced by external temperature especially sunlight. Hence buildings orientation is widely important for energy survival. If the building width is designed to north-south, energy consumption will occur in the best way.

External walls should also have filtering capability. So, external walls should have adjustable mobile parts and 
openings and it should have appropriate solution for air conditioning, lighting and storm rain.

\subsection{Harvesting Wind Energy}

Wind is a renewable energy source which can be advantageously tapped at higher altitudes of tall buildings where wind speed is considerably large. So that, a wind turbine can be installed at the body or high altitudes of skyscrapers to generate and produce needed power of the building.

\section{Case Studies}

Hereunder a few case study building examples are presented which represent the new generation of sustainable tall buildings that are setting trends for future projects incorporating innovations in materials and building systems. Understandably, this is not a fully comprehensive and global look, but the case studies provide angles though which to examine the movement.

\subsection{The Hearst Tower (New York City, US)}

The Hearst Tower is New York's first skyscraper to receive the gold LEED certification. Nearly 80 percent of the steel used to create this structure was recycled, as well as much of the interior's flooring and ceiling materials [15]. The diagrid triangular framing pattern provides superior stability with less material than the typical steel; the diamond-like shape of the structure also ensures copious amounts of sunlight are being taken advantage of.

The Hearst tower also makes excellent use of rainwater; the water comes from rainwater, and cools and humidifies the lobby air [16] “(Fig. 1").

\subsection{Bank of America Tower (New York City, US)}

This tower is one of the first skyscrapers that were built using largely recycled and recyclable material as well as being LEED Platinum certified [15], it can also be considered the greenest skyscraper yet in the entire country. This tower has an onsite cogeneration plant that produces two-thirds of the building's energy requirement. A sophisticated rain water capture system is also in place, as well as windows that maximize sunlight along with smart and efficient LED lighting [16] “(Fig. 2”).

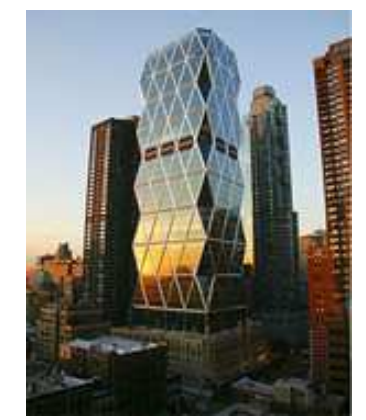

Figure 1. The Hearst Tower [16]

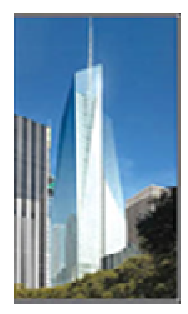

Figure 2. Bank of America Tower [16]

\subsection{The Pearl River Tower (Guangzhou, China)}

This skyscraper is known for its net zero-energy goal, meaning that it will conserve and generate enough power to meet its energy demands [16]. It has a curved glass façade that directs air flow through narrow openings in the facade that will drive large, stainless steel wind turbines to generate electrical energy. The building's aerodynamic shape, which resembles airplane wings turned vertically that serves to funnel wind into the tunnels [7] “(Fig. 3").

\subsection{The Burj al-Taqa (Dubai, UAE)}

This green skyscraper has a cylindrical shape that is designed to expose as little surface area to the sun as it can. A protective solar shield reaches from the ground to the roof and covers 60 percent of the building. It protects the side most affected from the sun's glaring rays. The remaining 40 percent has diffused light that is tempered by a mineral coating on the windows [16]. The building also has an incredible air conditioning system that draws the air from outside and cools it with seawater before distributing it around. Finally, there will be a 60-meter turbine on the tower roof and two photovoltaic facilities that will produce the electricity to meet the needs of the building [16] "(Fig. 4").

\subsection{The Lighthouse Tower (Dubai, United Arab Emirates)}

Designed by the Atkins Group and standing at an astonishing 400 meters with 66 floors [16]. The Dubai International Financial Center plans on inhabiting this skyscraper dubbed in this tower [15]. The green skyscraper will house three large $225 \mathrm{~kW}$ wind turbines, which are 29 meters in diameter, located on the south facing side of the structure. In addition to the wind turbines, there will also be 4,000 solar panels to generate additional energy needed to accompany the skyscrapers daily operations. The tower hopes to reduce its overall energy consumption by $65 \%$ and its water consumption by $40 \%$ when compared to an equivalent building of the same magnitude [16] "(Fig. 5").

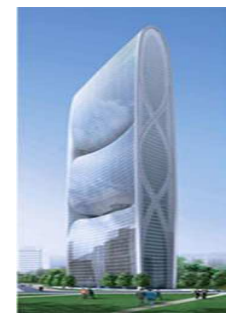

Figure 3. The Pearl River Tower [7] 


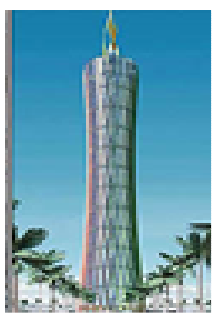

Figure 4.The Burj al-Taqa [16]

\subsection{World Trade Center Towers (Manama, Bahrain)}

The Bahrain World Trade Center is first skyscraper in the world to integrate wind turbines into its design. Three different bridges, all of which house a 29-meter turbine, connect two separate towers. These towers face north to capture the winds from the Persian Gulf. The building assumes a sail shape so as to maximize the amount of wind funneled through the towers. The " $S$ " shape flow is ideal because it ensures that any wind coming within a 45 degree angle to either side will Create a wind stream that is perpendicular to the turbines. These turbines are intended to provide $11 \%$ to $15 \%$ of the towers total power consumption [16] "(Fig. 6").

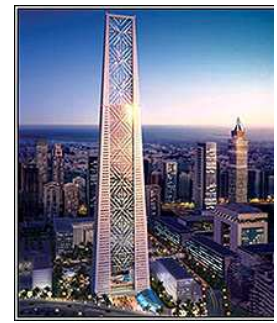

Figure 5. The Lighthouse [16]

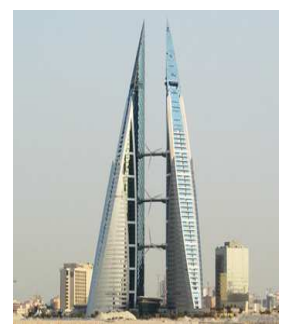

Figure 6. World Trade Center [15]

\subsection{CIS Tower (Manchester, England)}

The Co-operative Insurance Solar Tower in Manchester, England set a new benchmark by retroactively installing renewable energy technology onto the service tower during a renovation in 2006. Boasting over 7000 solar panels and 24 wind turbines, the CIS tower no doubt represents a stunning achievement in what be accomplished when you combine skyscrapers and clean technology.

Currently, the structure can generate more than $10 \%$ of the energy it needs, but it's still a technological marvel that serves as a great example of integrating renewable energy technologies into pre-existent architectural design [15] "(Fig. 7").

\subsection{Chicago's 340 on the Park (Chicago, US)}

Chicago's 340 on the Park is the first residential tower in Mid-western America to attain the silver LEED certification. Featuring high tech insulation and rainwater capture systems, this structure really sets the environmental benchmark for residential skyscrapers in the US.

340 on the Park was designed with the energy consuming human in mind, and thus integrates only the most efficient of technologies within the living and common spaces; there's even a two story winter garden starting on the 25 th floor that makes great use of the special windows designed for optimal sunlight dispersion throughout the building [15] "(Fig. 8").

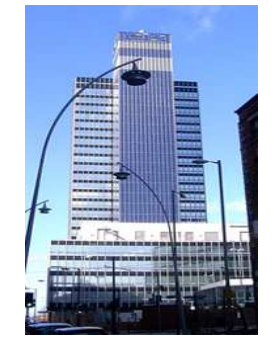

Figure 7. CIS Tower [15]

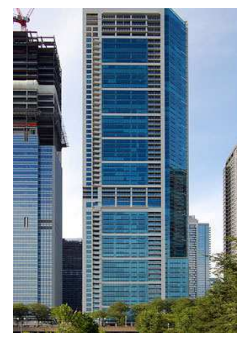

Figure 8. 340 on the Park [15]

\section{Discussion and Conclusion}

Following scientists warnings about consequences of change in climate conditions including (increase in temperature, flooding, draught, acceleration in polar ice melting, reduce in diversity of living creatures) and increased consumption of fossil fuels in the world, renewable energy compatible with climatic conditions has become more important. The best chance for the survival of the developed countries seems to lie with the built environment because buildings in use or under construction are the greatest single indirect source of carbon emissions [2]. It is estimated that world population will be 9 billion till year 2050 and $75 \%$ of this population will live in urban areas. This problem introduces the issue of supplying food for this population and their need for cultivable land, vertical development methods instead of horizontal development.

This study examines that if the future skyscrapers want to be compatible with different conditions, then they should be flexible. These populated buildings require more attention and they should be constructed skillfully and with consideration of environment conservation as ecological or green buildings. The initial cost of integrated green tall buildings may be 5 to 
10 percent higher than that of a conventional building, but the long-term lower operational cost makes it justifiable [2].

By reducing both embodied and operational energy demands of tall buildings and the infrastructure, the life-cycle energy consumption can be reduced. Sustainability of tall buildings must therefore be viewed as an integral part of the city's sustainable growth.

\section{References}

[1] M. Zandi, S. Parvarinezhad, "Sustainable Development and Its Concepts in Residential Architecture of Iran, " Journal of Housing and Village Environment, vol. 13, 2010, pp. 2-21.

[2] UNITED NATIONS, "Future World Population Growth to be Concentrated in Urban Areas," United Nations Population Division Report, March, 2001

[3] Y. Gorji Mahlabani, "Sustainable Architecture and Its Criticism in the Field of Environment, " Research and Scientific Journal of Scientific Architectural and Urban Development Association of Iran, vol.1, 2010, pp. 91-100,

[4] M. Seyyed Almasi, "Research Thesis of the Necessity of Sustainable Architecture in Universities of Iran, " $\mathrm{PhD}$ Thesis, Islamic Azad University of research and Sciences Tehran, 2009

[5] Sh. Shayesteh, "Green Architecture," Jahade Daneshgahi Publication of Mashhad, Mashhad, 2006

[6] B. Donaldson, P. Lippe, "Process and Integration. Lessons Learned: High Performance Buildings," The Durst Organization. New York, NY, 2000
[7] M. Ali, P. J. Armstrong, “ Overview of Sustainable Design Factors in High-Rise Buildings, " CTBUH 8th World Congress, 2008

[8] N. Hamidreza, "Thoughts in Art and Architecture, "University of Science and Industry of Iran, Tehran , 2004

[9] M. Akbari Yeganeh, "Introducing Evaluation Systems for Building Quality in Other Countries,” Tehran, 2011,

[10] E. Asnaashari, “ Certificate of Energy Management and Environmental Design, " Semnan, 2012

[11] L.S. Beedle, M.M. Ali and P.J. Armstrong, "The Skyscraper and the City: Design, Technology, and Innovatio," Edwin Mellen Press. Ceredigion, U.K and Lewston, NY, 2007

[12] M.M, ALI, “ Art of the Skyscraper: The Genius of Fazlur Khan. Rizzoli," New York, 2001

[13] U. Behr, "Double Facades for High Buildings. Tall Buildings Beyond 2000" vol. a. Urban Habitat and High-rise, TBMa, 1994-1999, A. Awang et al. Editors, Institute Sultan Iskandar, Malaysia, 2001

[14] W. Pank, H. Girardet and G. COX, " Tall Buildings and Sustainability", Report to Corporation of London, London, U.K., March, 2002

[15] V. T. Barrera, "Ten of the Greenest Skyscrapers in the World", Energy Trends Insider, May, 2009

[16] N. Foster, S. Luff, D. Visco, "Green Skyscrapers What is being built, and why? ", A report for CRP 3840: Green Cities, Cornell University, December, 2008 